\title{
3D PRINTING STRATEGIC DEPLOYMENT: THE SUPPLY CHAIN PERSPECTIVE
}

\begin{abstract}
Purpose - The emergence and application of 3D Printing (3DP) is changing the way products are developed and reach the customer, allowing for unprecedented customisation options. Past research has focused on the modus operandi of the technology, providing indications for wider future adoption. 3DP is predicted to complement current production processes and is anticipated to have a profound effect on the value chain, and therefore, on Supply Chain (SC) management. Management-related 3DP research has, however, been largely fragmented in terms of analysing the strategic deployment of 3DP and the corresponding effects on performance objectives.
\end{abstract}

Design/methodology - The approach taken is a critical literature review, synthesizing and interpreting past research on cross-industry deployment of 3DP, including illustrative examples. This enabled the development of a framework of current stage knowledge.

Findings - Building on past research we propose a conceptual framework to be used as a classification system for 3DP operations, based on process and SC level configurations across different industries. We discuss the potential impact on operations performance objectives and then highlight research gaps, proposing specific research avenues to enhance understanding of the effects of 3DP adoption on SCs.

Practical implications - The proposed framework outlines strategic guidelines for 3DP and provides practitioners with the range of strategic options available for 3DP deployment and anticipated impacts on performance.

Originality/Value - The framework can be used to map 3DP deployment at an operational level and to identify the likely impact on performance objectives. Relevant implications and a future research agenda are explored.

Keywords SCM framework, strategy, operations

Category of the paper: Viewpoint

\section{Introduction}

3D Printing (3DP) is an additive manufacturing process with products built by layering crosssectional slices (Berman, 2012; Graham et al., 2015). A variety of 3DP technologies are available, including Stereolithography (SLA), Selective Laser Sintering (SLS), Drop on Demand (DOD), Fused Deposition Modelling (FDM), Binder Jetting, and Laminated Object Modelling (LOM). Their suitability for application depends on a variety of factors such as the industry sector, the product itself and the dynamics of competition in the specific context (Kruth et al., 1998; Petrovic et al., 2011). Despite the technological advances that have been made in these technologies, major obstacles to widespread adoption of 3DP remain, including the high acquisition costs of machines and raw materials, a limited raw material range, legal and regulatory issues, and the slow build/process speed (Holmström and Partanen, 2014; Kietzmann, et al., 2015; Attaran, 2017). These obstacles make the technology currently less 
competitive (and hence less attractive) than traditional manufacturing counterparts for many industrial applications.

However, 3DP also possesses valuable attributes that already make it a viable option in some industries. For instance, the ability to produce complex bespoke geometries makes it attractive to the medical sector, where end user customisation is critical (e.g. replacement joints, hearing implants and teeth). Similarly, the ability to produce lightweight parts is particularly advantageous for aerospace and automotive industry applications (Petrick and Simpson, 2013). MacCarthy et al. (2016) identify technology as a factor that may affect Supply Chain (SC) configuration and evolution. A generic advantage of the 3DP technology is that it eliminates the need for expensive tooling, thereby reducing costs and risks related to new product introduction (Khajavi et al., 2015). By essentially shrinking the SC distance, adverse factors such as risk, uncertainty and planning errors associated with traditional distributed and extended SCs can be significantly reduced. 3DP also reduces SC complexity by replacing previously assembled parts, sourced from multiple suppliers, with single components (Conner et al., 2014). In the following sections we develop a conceptual framework for the strategic deployment of 3DP and discuss its implications for academia and practice.

\section{Research imperative}

Researchers have considered the economic feasibility of deploying the technology in contemporary manufacturing operations (Atzeni and Salmi, 2012; Lindemann et al., 2012; Wittbrodt et al., 2013; Khajavi et al., 2014, 2015) and have explored combinations with traditional technologies to improve operational performance (Karunakaran et al., 2010; Kerbrat et al., 2011; Khajavi et al., 2015). Research has also focused on conceptualising changes to rules, structures and relationships between SC members resulting from the introduction of 3DP (Holmström and Partanen, 2014; Nyman and Sarlin, 2014; Sasson and Johnson, 2016; Rogers, et al. 2017). Notwithstanding, there is a gap between research and practice in relation to current 3DP deployment approaches followed across different industries, and how they impact the development of SC management theory (Potter et al., 2015; Rogers et al., 2016). To date, comparatively little attention has been focused on 3DP issues in the specific contexts of SC. The need to identify the impact of 3DP on SCs at a strategic level to better understand performance implications remains crucial for the deployment of these technologies (e.g. Holmström and Partanen, 2014; Holmström, et al., 2016; Rogers, et al. 2017).

3DP research has, to date, been largely fragmented in terms of analysing the strategic deployment of 3DP and the corresponding effect it has on operational performance objectives (Holmström et al., 2010; \& Khajavi et al., 2014). As a result, the literature lacks a consolidated proposition that identifies the performance objectives that can be enhanced by the strategic deployment of 3DP capability at the intra and inter-organisational level (D'Aveni, 2015, Holmström et al., 2016). More specifically, there has been no theoretical framework to explain the strategic rationale for pursuing a 3DP-based SC strategy to achieve specific performance objectives (i.e. cost, flexibility, speed), and hence competitive advantage. Future research needs to identify how new technologies can be introduced to obtain operational benefits and how these technologies can be combined with existing operational practices in novel combinations to deliver performance improvements (Holmström and Romme, 2012). In that respect, an understanding of the relationships between 3DP capabilities and performance at different levels of contemporary manufacturing operations could be insightful. Hence, this paper aims to identify, define, and exemplify typical 3DP deployment strategies pursued. Here we propose a conceptual framework that seeks to explain current practice in 3DP deployment. The 
framework can also be used to provide strategy level guidelines for prospective 3DP implementation projects.

\section{Current state of 3D printing deployment}

Most of the operations management research in the field of 3DP has focused on the feasibility and effects of deploying the technology in contemporary manufacturing settings and SCs. From the extant literature reviewed, issues raised by researchers can be broadly classified as relevant to either the 'process level' or the 'SC level'.

\subsection{The Process Level}

The process level refers to the deployment capability of 3DP as a functional resource unit, namely whether the 3DP machine can work on its own or whether it requires the interaction with traditional technology. The unit of analysis is the 3DP machine, which may be in one of two configurations; namely a standalone configuration or a combinational configuration. At this process level, 3DP can function as a standalone unit or be used in conjunction with other units of technology. Below is a review of the literature of these two configurations.

a) Standalone Configuration: This configuration refers to a functionally-oriented 3DP machine operating alone. There are examples of standalone 3DP configurations present in the spare parts $\mathrm{SC}$ of the aerospace industry and isolated systems, such as space stations and battlefields (Pérès and Noyes, 2006; Holmström et al., 2010; Khajavi et al., 2014). In these situations, the capability of 3DP to make products on-demand has a significant impact on reducing inventory holding and obsolescence costs. In isolated systems, the remoteness (e.g. space station) and inaccessibility of the service site (e.g. battlefield) are overriding factors that justify the deployment of 3DP manufacture (Pérès and Noyes, 2006). A notable example of 3DP deployment in an isolated environment is the building of a tool (ratchet wrench) in space with a 3D printer using a design file transmitted from earth by NASA (Harbaugh, 2017). A further example is the Mobile Parts Hospital (MPH) developed by the U.S. Army's National Automotive Centre and the Centre for Advanced Technologies in Detroit, Michigan. This is essentially a compact communications and manufacturing unit that utilises 3DP to produce repair parts on-demand in remote locations. The first MPH was deployed in Camp Arifjan, Kuwait, to support the American forces in Iraq (Pérès and Noyes, 2006). Standalone configurations are offered by 3DP service providers such as Materialise, Sculpteo, Shapeways and Thingiverse that utilise e-commerce platforms to pool customer orders to be manufactured in centralised facilities with an array of 3D printers. This enables capacity maximisation via printing multiple products in one build operation (Rayna and Striukova, 2014). Local 3DP services offered by companies such as Stratasys and Staples are other examples of standalone 3DP deployment, as is home 3D printing.

b) Combinational Configurations: In this configuration, the 3DP machine works alongside traditional tool-based production technologies to achieve a variety of objectives. The adoption of 3DP by manufacturers has been predicted to be a gradual process, whereby the capabilities of tool-based manufacturing will be complemented to improve operational performance until the technology matures to the extent that it becomes a viable economical alternative to traditional manufacturing (Petrick and Simpson, 2013; Holmström, et al., 2016). Although for some industries this will take time, in the case of certain personalised medical products 3DP has already been fully adopted as a strategic requirement to remain competitive. An example of this can be found in the U.S. hearing-aid industry which converted to $100 \%$ additive 
manufacturing in less than 500 days (D'Aveni, 2015). Researchers have explored a number of 3DP and traditional manufacturing combinations. For instance, Khajavi et al. (2015) proposed a hybrid combination of 3DP and traditional tool-based manufacturing for product introduction. Using scenario modelling, it was demonstrated that the hybrid combination reduces risks associated with uncertainties and market acceptance when 3DP is deployed at the product introduction phase.

The above-mentioned configurations demonstrate complementary technologies functioning separately as two autonomous units, working on separate products or parts at a time. However, a further combination also exists, whereby both technologies function as one unit to manufacture a product. In 2010, Karunakaran et al. (2010) presented a hybrid-manufacturing configuration where additive and subtractive manufacturing processes worked in parallel to function on the same Computer Numerical Control (CNC) machine to address inefficiencies associated with having both processes separated for the manufacture of metallic moulds. This configuration is used to overcome the trade-offs of quality and automation that comes with using the technologies separately. CNC machines require considerable human intervention to generate programs, making it a slow and costly (but dependable) route, whilst 3DP technology is not sufficiently accurate for high precision applications such as tooling. The high accuracy and finish quality of the CNC machine, taken together with the high automation level of 3DP resulted in $42 \%$ less time and $28 \%$ less cost than the traditional CNC manufacturing approach. Other examples of similar applications have been reported with the aim of improving performance in the usual core attributes of cost, speed and quality (Hur et al., 2002; Song and Park, 2006).

\subsection{The Supply Chain Level}

The unit of analysis at this configuration level is the 3DP production facility, which may contain 3DP machines in either standalone, combinational or both configurations. The following SC configurations have been proposed for 3DP deployment at the supply chain level.

a) Centralised Configuration: In this configuration, 3DP facilities are centralised to serve multiple demand locations. Centralised 3DP configurations exist in the aerospace spare parts $\mathrm{SC}$, where 3DP equipment is deployed in distribution centres to cover multiple service locations to cover demand of slow-moving spare parts (Khajavi et al., 2014). For instance, several naval air stations and master jet bases across the United States are served from one Boeing production facility in California (Khajavi et al., 2014). Aggregating demand from various service locations ensures that the investment in 3DP capacity is well utilised. However, the disadvantage of this configuration is that the produced parts need to be shipped to the service locations, resulting in increased response times (Huang et al., 2013). This is critical as the costs of 'unavailability' or downtime - particularly in the aerospace industry - are very high, meaning spare parts need to be readily available to keep flights in operation (Pérès and Noyes, 2006). Initial 3DP deployment in this context is likely to be centralised because of the low number of 3DP parts produced and also the high personnel and machine acquisition costs (Holmström et al., 2010). This view was verified by Khajavi et al. (2014) who found that centralised deployment is economically feasible with the current state of 3DP technology. Centralised configurations are also common with 3DP service companies (e.g. Materialise and Shapeways) that operate centralised production factories with an array of 3DP machines. Customers' design orders are pooled via e-commerce websites and verified for printability, which are then arranged and scheduled on the 3DP equipment in such a way that the build envelope is maximised. 
Afterwards, orders are packaged and shipped to the customer's doorstep through a logistics service provider (Rayna and Striukova, 2014).

b) Distributed Configuration: The concept of distributed production indicates a shift in consumption and production patterns away from conventional mass production, with its long, linear SCs, economies of scale and 'centralising' tendencies. There appears to be lack of clear consensus on this topic but the basic idea is towards decentralisation of production sites to ensure a closer proximity to market locations (Kohtala, 2015). This production model is enabled by $3 \mathrm{DP}$ because of its capability to produce small batches economically, owing to the absence of costly setups and tooling (Berman, 2012). This is referred to as 'economies of one' (Petrick and Simpson, 2013) and is a configuration that is suitable when the demand of 3DP producible parts is sufficiently high to justify the capacity investment. The advantage is that it eliminates inventory holding and transportation costs (e.g. Holmström et al., 2010; Huang et al., 2013; Khajavi et al., 2014), as well as providing fast response times (e.g. Pérès and Noyes, 2006; Huang et al., 2013; Wittbrodt et al., 2013; Bogers et al., 2016; Harbaugh, 2017). Here 3DP facilities are deployed close to service locations or machines are deployed on-site. Therefore, the distributed configuration can be broadly classified, based on the operation's closeness to the service site (i.e. hub-based) or the location of the 3DP operation on the service site (i.e. onsite). Local production is enabled due to the reduction of the 'minimum efficient scale', in contrast to traditional 'economies of scale' models, where production stages are separated and geographically dispersed (Cotteleer and Joyce, 2014). The hub-based configuration uses the same principle as the centralised configuration in pooling demand from neighbouring locations to utilise 3DP capacity. The difference, however, is that the hub-based configuration is of a smaller and more local scope (Hopkinson et al., 2006, p. 162). This configuration reduces delivery times and is the strategy used by 3D printing service companies such as 3D Hubs and MyMiniFactory to satisfy consumer demand for local printing services.

The feasibility of this strategy has also been conceptualised for the automotive industry, where the production of legacy parts can be outsourced to local contract printer farms (Savastano et al., 2016). On-site deployment was conceptualised by Holmström et al. (2010) as a distributed configuration for aerospace spare parts SCs. In this scenario, 3DP machines are located on the service site to produce parts when needed. It was, however, criticised in the study by Khajavi et al. (2014) as uneconomical, owing to the high operating costs associated with 3DP machines at each service site, as well as low capacity utilisation (e.g. Holmström et al., 2010; Khajavi et al., 2014; Mellor et al., 2014; Rayna and Striukova, 2016; Rogers et al., 2016). Interestingly, research exists that contradicts the conclusion reached by Khajavi et al. (2014) about the uneconomic distributed configuration, albeit in different contexts and with different cost models (e.g. Wittbrodt et al., 2013). In the context of home 3D printing the distributed configuration has been demonstrated to be feasible through the use of low-cost open source 3D printers (Wittbrodt et al., 2013), to the extent that it becomes a more cost-effective alternative for products in the consumer market (Petersen et al., 2017). Further, breakthroughs in low-cost process technology alternatives could make the distributed strategy commercially viable for production of commonly used electronic components (Flowers et al., 2017). The main point here is that deployment strategies largely depend on application contexts and cost perspectives.

The 3DP configurations at the process and SC level, as described above, are summarised in Figure 1 .

\section{- Insert Figure 1 here -}




\section{A framework for the strategic deployment of 3D printing}

To assist with analysis of the strategic deployment of operations that adopt any of the four 3DP configurations at the process and SC levels, as shown in Figure 1, a two-by-two matrix is proposed. This consists of quadrants A, B, C, and D (see Figure 2). The X and Y axes correspond to different performance dimensions of the operation. These four quadrants also represent operations performance scenarios and evidence from the literature suggests values for the performance dimensions when deploying each of the identified 3DP deployment strategies defined in the four quadrants.

\section{- Insert Figure 2 here -}

\subsection{Combinational Distributed Strategy}

As one would expect, the appropriate combinational configuration strategy varies according to the specific objectives and/or type of manufacturing operations. Documented examples are the 'series combination' of 3DP with traditional manufacturing to reduce the risk and cost of failure associated with new product introduction (Khajavi et al., 2015), a 'parallel combination' of 3DP and traditional manufacturing to isolate disruptions from low-volume part production (Sasson and Johnson, 2016), and the introduction of 3DP to complement the capacity of traditional manufacturing for the production of standard, personalised and customised final products (Chiu and Lin, 2016). These configurations typically serve to improve the efficiency (i.e. improved speed and reduced cost) and flexibility of a manufacturing operation (e.g. Khajavi et al., 2015; Chiu and Lin, 2016; Sasson and Johnson, 2016).

Other combinations exist in which 3DP and traditional manufacturing are combined to function as one combined unit. Examples include the combination of 3DP and traditional manufacturing processes on the same CNC machine for the production of metallic moulds (Karunakaran et al., 2010) and similar ones adopted for prototyping (Hur et al., 2002; Song and Park, 2006). In addition to enhancing the build speed of the manufacturing process, these combinations improve the quality of products (e.g. Hur et al., 2002; Akula and Karunakaran, 2006; Song and Park, 2006; Xiong et al., 2009; Karunakaran et al., 2010; Kerbrat et al., 2011; Hibbert, 2014). As stated earlier, enablement of distributed production is predicated on the reduction in the acquisition costs of 3DP machines and increases in automation levels (Khajavi et al., 2014). Extending the same principle to the combinational configuration indicates that the proliferation of production facilities with this kind of setup depends on unit costs of the combined units. The combination suggested by Sasson and Johnson (2016) was considered expensive because of the up-front investments in 3DP and traditional manufacturing technologies. Distributing production facilities with this setup may be prohibitively costly; however, some combinations could become more economical to distribute in the future. For instance, the 'Wire plus Arc Additive Manufacture (WAAM)' developed by BAE Systems and Cranfield University is highly economical in terms of material costs/waste reduction, especially in comparison to powder-based 3DP technologies such as SLS and traditional subtractive manufacturing processes such as milling (Hibbert, 2014, p. 47). The major advantage of the distributed configuration is close proximity to service locations, which results in fast response times and low transportation costs. As a result, a distributed 3DP deployment strategy enhances customer satisfaction, adding value on the intangible aspects of quality (e.g. Pérès and Noyes, 2006; Wittbrodt et al., 2013; Bogers et al., 2016; Harbaugh, 2017). The downside is the potentially low capacity utilisation of 3DP resources. Therefore, the combination of the capabilities of the 
combinational process configuration and the distributed SC configuration yields the operations scenario given by the values of performance dimensions in quadrant $\mathrm{A}$.

\subsection{Combinational Centralised Strategy}

Operations deploying a Combinational Centralised Strategy (quadrant B) differ from their counterparts deploying a Combinational Distributed Strategy (quadrant A) only in the SC configuration. The expensive nature of the combinational configuration could provide justification to centralise capacity. Also, it provides the structure to pool demand from several service or market locations, to ensure high capacity utilisation of resources in the centralised facility. However, the disadvantage is that production facilities are distant from service locations, meaning increased response times and transportation costs. Therefore, a combinational process configuration used together with a centralised SC configuration yields the performance scenario given in quadrant B. As indicated earlier, the combinational configuration provides higher flexibility and better product quality over the standalone configuration. Process speed is comparatively faster but the delivery speed is lower, owing to proximity to market locations, which consequently leads to higher transportation costs (Huang et al., 2013; Hibbert, 2014). Capacity utilisation of resources is higher compared to the distributed configuration because demand is pooled from a wider area of service locations. This indicates that the Combinational Centralised Strategy will be preferable until the technology matures. Although still in the development phase, it appears that BAE systems deploys WAAM in this configuration with a facility owned and operated by a defence and aerospace giant, Lockheed Martin (Hibbert, 2014).

\subsection{Standalone Distributed Strategy}

Operations in quadrant $\mathrm{C}$ are characterised by high production costs (personnel and equipment) because more 3DP resources are deployed close to service locations and/or on-site (e.g. Khajavi et al., 2014; Rayna et al., 2015; Steenhuis and Pretorius, 2016). Furthermore, capacity utilisation of these 3DP resources is low, due to localised positioning of facilities which makes it uneconomical to serve distant market locations (Khajavi et al., 2014). However, there is scope to increase capacity utilisation, for instance, through the adoption of cooperative strategies, such as 'Ad-Hoc Cooperation', 'Cooperative Pooling' and 'Commercial Pooling', with general purpose 3DP machines capable of producing a diverse mix of parts for the aerospace industry (Kilpi et al., 2009; Holmström et al., 2010). As with the Combinational Distributed Strategy (quadrant A), the main advantages of the Standalone Distributed Strategy (quadrant C) include fast response times and low transportation costs. However, the operation is less flexible and also production lead time is higher owing to the comparatively slow build speed. In terms of product quality, the standalone configuration has been shown to fabricate products with inferior structural properties compared to its combinational counterpart, making it less suitable for safety-critical parts such as aircraft wings (Mehnen et al., 2014). This would not be a prime concern in many applications in the consumer industry where the product quality requirements are comparatively less stringent (Petersen et al., 2017). This combination (standalone process and distributed SC, i.e. quadrant C) was described as a future potential implementation for 3DP in the spare parts SC of the aerospace industry, which will be economically viable when unit costs of 3DP machines fall appreciably and automation levels increase to reduce the labour content significantly. A similar trend is observed in the food industry, where machine and material costs of commercial food printing platforms are currently very high (Sun et al., 2015). That said, there may exist some overriding factors apart from cost that justify on-site 3DP deployment; a good example of which is inaccessible locations. This is also a future vision of 
3DP deployment. At a consumer rather than business level, a good example of a standalone distributed strategy is home 3D printing. This has been enabled by the ever-increasing affordability of 3D printers for domestic use (e.g. Rayna and Striukova, 2014).

\subsection{Standalone Centralised Strategy}

As discussed earlier, process configuration cost is a major determinant in terms of which SC configuration to use. Highly capital-intensive process configurations tend towards centralisation, while significantly less capital-intensive ones could be distributed in the SC. Other factors, such as the level of criticality of the service the operation supports also play a role. For instance, availability of spare parts is very critical in the aerospace industry, owing to very expensive downtime costs. When pursuing a Standalone Centralised Strategy (quadrant D), the 3DP operation is capable of producing parts/products, albeit with relatively inferior structural qualities using the relatively slow build speed offered by standalone 3DP. This is unsuitable for safety critical parts. As with the Combinational Centralised Strategy (quadrant B), in the case of the Standalone Centralised Strategy capacity utilisation of 3DP resources is high, however, with high transportation costs and slower response times. This configuration is currently being deployed by Boeing to manufacture air-cooling ducts (environmental control system) for the Super Hornet fighter jet. The company maintains a centralised facility in California, USA that covers 20 service locations consisting of naval air stations and master jet bases (Khajavi et al., 2014). It is also the strategy deployed by 3D printing service companies such as Shapeways, Sculpteo, Materialise, etc. These companies utilise e-commerce platforms to pool customer demand globally for production in centralised facilities. This also enables the maximisation of the build envelope, where different products can be fabricated in a single build operation (Rogers et al., 2016).

\section{Conclusions, implications and a future research agenda}

In summary, this paper identifies, defines, and exemplifies the typical 3DP deployment strategies proposed in the literature with examples that have emerged in practice. The conceptual framework consolidates the set of strategic choices at the intra-organisational level, i.e. the process level, and the inter-organisational level, i.e. the SC, when deploying 3DP capability. It also highlights the implications for performance by identifying the anticipated competitive priorities for operations and SCs. From a theoretical point of view, this paper demonstrates the value of analysing operations at the process and SC levels and provides insights on deploying 3DP capabilities at these two levels. The key theoretical contribution is the development of a conceptual framework for classifying and analysing 3DP operations. This framework serves as an aid in explaining the performance of operations deploying 3DP capability at the process and SC levels. This should prove useful for better focusing empirical studies carrying out strategic analysis of 3DP operations for different applications. In that respect, we make a theoretical contribution in the context of SC management by developing a "mid-range" theory (Boer et al., 2015, p. 1248). The paper can serve to inform future research, as it is the first to present a 3DP deployment strategies framework in the SC context. Using four deployment strategies, we conceptualise the typical configurations employed when using 3DP and describe the corresponding implications for performance objectives. The combinational deployment of 3DP capability (i.e. in the form of the Combinational Centralised Strategy or the Combinational Distributed Strategy) results in higher flexibility and better product quality, as it overcomes the deficiencies of a 3DP standalone deployment (i.e. the Standalone Centralised Strategy or the Standalone Distributed Strategy). Furthermore, the distributed deployment of 3DP capability (i.e. in the form of either the Standalone Distributed Strategy or the 
Combinational Distributed Strategy) constitutes a more advanced level of 3DP capability deployment in the SC. It results in specific benefits over the centralised deployment (i.e. the Standalone Centralised Strategy or Combinational Centralised Strategy), as it reduces transportation costs, enhances response time and better serves the customer, hence adding value beyond the tangible product itself. However, such a deployment increases personnel and machine acquisition costs, and typically results in low capacity utilisation.

To use a printer industry analogy, we are probably still in the 'dot matrix' era of 3DP capability; however, further technological developments and a reduction in the acquisition costs are needed for the technology to be a viable option in most manufacturing settings in the future. Hence, the framework can provide practitioners with high level strategy guidelines for prospective 3DP implementation projects. It presents practitioners with the current range of strategies available for 3DP deployment at the process and SC levels, as well as with anticipated relative impacts on performance. In that respect, the framework can serve as a decision-making tool, both in terms of strategy selection, as well as in assessing likely performance trade-offs or in performing cost-benefit analyses. By building up specific use cases, this framework will be able to inform and guide future 3DP implementation.

Given the paper's conceptual nature, future research should focus on conducting case study analyses using the proposed framework, and identify and discuss wider implications for practice and for society more broadly. This will provide detailed information on 3DP deployment and should focus on gaining insights into a range of industries that are adopting 3DP, including the automotive, dental, medical and sporting goods industries. Future research could also explore the impact of 3DP on SC configuration and coordination. Additional research avenues could be to investigate the implications of 3DP deployment and its implications on SC structures, namely the collapse of SC tiers, the physical location of suppliers and the corresponding distribution network and location of production facilities. Many existing models have focused on future possibilities of 3DP but excluded raw material suppliers (Khajavi et al., 2014). There is also limited understanding of inventory management techniques and procedures at the factory and SC level for 3DP operations (Rogers et al., 2016) and the implications of 3DP on traditional inventory management concepts (Holmström et al., 2016). Future research could also examine the applicability of current techniques and procedures to stocking raw materials (such as filaments or powders), stocking/dispatching finished products and the potential impact on work-in-progress, with particular emphasis on identifying the impact on production speed and efficiency.

\section{References}

Akula, S. and Karunakaran, K.P. (2006), "Hybrid adaptive layer manufacturing: An Intelligent art of direct metal rapid tooling process", Robotics and ComputerIntegrated Manufacturing, Vol. 22 No. 2, pp. 113-123.

Attaran, M. (2017) "The rise of 3D printing: The advantages of additive manufacturing over traditional manufacturing", Business Horizons, Vol. 60 Iss. 5, pp. 677-688.

Atzeni, E. and Salmi, A. (2012), "Economics of additive manufacturing for end-usable metal parts", The International Journal of Advanced Manufacturing Technology, Vol. 62 No. 9, pp. 1147-1155.

Berman, B. (2012), “3-D printing: The new industrial revolution”, Business Horizons, Vol. 55 No. 2, pp. 155-162. 
Boer, H., Holweg, M., Kilduff, M., Pagell, M., Schmenner, R. and Voss, C. (2015), "Making a meaningful contribution to theory", International Journal of Operations \& Production Management, Vol. 35 No. 9, pp. 1231-1252.

Bogers, M., Hadar, R. and Bilberg, A. (2016), "Additive manufacturing for consumer-centric business models: Implications for supply chains in consumer goods manufacturing", Technological Forecasting and Social Change, Vol. 102, pp. 225-239.

Chiu, M.-C. and Lin, Y.-H. (2016), "Simulation based method considering design for additive manufacturing and supply chain: An empirical study of lamp industry", Industrial Management \& Data Systems, Vol. 116 No. 2, pp. 322-348.

Conner, B.P., Manogharan, G.P., Martof, A.N., Rodomsky, L.M, Rodomsky, C.M., Jordan, D.C., Limperos, J.W. (2014), "Making sense of 3-D printing: Creating a map of additive manufacturing products and services", Additive Manufacturing, Vol. 1 No. 4, pp. 64-76.

Cotteleer, M. and Joyce, J. (2014), "3D opportunity: Additive manufacturing paths to performance, innovation, and growth", Deloitte University Press, 17 January, available at: http://dupress.com/articles/dr14-3d-opportunity/ (accessed 15 July 2017).

D’Aveni, R. (2015), “The 3-D Printing Revolution”, Harvard Business Review, May, pp. 4048.

De Jong, J.P. and De Bruijn, E. (2013), "Innovation lessons from 3-D printing", MIT Sloan Management Review, Vol. 54 No. 2, pp. 43-52.

Flowers, P.F., Reyes, C., Ye, S., Kim, M.J. and Wiley, B.J. (2017), “3D printing electronic components and circuits with conductive thermoplastic filament", Additive Manufacturing, Vol. 18, pp. 156-163.

Graham, G., Mehmood, R. and Coles, E. (2015), "Exploring future cityscapes through urban logistics prototyping: a technical viewpoint", Supply Chain Management: An International Journal, Vol. 20 No. 3, pp. 341-352.

Harbaugh, J. (2017), "Space Station 3-D Printer Builds Ratchet Wrench To Complete First Phase of Operations", NASA, available at: http://www.nasa.gov/mission_pages/station/research/news/3Dratchet_wrench (accessed 28 September 2018)

Hibbert, L. (2014), “3d Printing Takes Off”, Professional Engineering, Vol. 27 No. 2, pp. 4548.

Holmström, J., Holweg, M., Khajavi, S.H. and Partanen, J. (2016), "The direct digital manufacturing (r)evolution: definition of a research agenda", Operations Management Research, Vol. 9 No. 1, pp. 1-10.

Holmström, J. and Partanen, J. (2014), "Digital manufacturing-driven transformations of service supply chains for complex products", Supply Chain Management: An International Journal, Vol. 19 No. 4, pp. 421-430.

Holmström, J., Partanen, J., Tuomi, J. and Walter, M. (2010), "Rapid manufacturing in the spare parts supply chain: Alternative approaches to capacity deployment", Journal of Manufacturing Technology Management, Vol. 21 No. 6, pp. 687-697.

Holmström, J. and Romme, A.G.L. (2012), "Guest editorial: Five steps towards exploring the future of operations management", Operations Management Research, Vol. 5 No. 1-2, pp. 37-42.

Hopkinson, N., Hague, R. and Dickens, P. (Eds.). (2006), Rapid Manufacturing: An Industrial Revolution for the Digital Age, John Wiley \& Sons.

Huang, S.H., Liu, P., Mokasdar, A. and Hou, L. (2013), "Additive manufacturing and its societal impact: a literature review", The International Journal of Advanced Manufacturing Technology, Vol. 67 No. 5-8, pp. 1191-1203. 
Hur, J., Lee, K., Zhu-hu and Kim, J. (2002), "Hybrid rapid prototyping system using machining and deposition", Computer-Aided Design, Vol. 34 No. 10, pp. 741-754.

Jiang, R., Kleer, R. and Piller, F.T. (2017), "Predicting the future of additive manufacturing: A Delphi study on economic and societal implications of 3D printing for 2030", Technological Forecasting and Social Change, Vol. 117, pp. 84-97.

Karunakaran, K.P., Suryakumar, S., Pushpa, V. and Akula, S. (2010), "Low cost integration of additive and subtractive processes for hybrid layered manufacturing", Robotics and Computer-Integrated Manufacturing, Vol. 26 No. 5, pp. 490-499.

Kerbrat, O., Mognol, P. and Hascoët, J.-Y. (2011), "A new DFM approach to combine machining and additive manufacturing”, Computers in Industry, Vol. 62 No. 7, pp. 684 692.

Khajavi, S.H., Partanen, J. and Holmström, J. (2014), "Additive manufacturing in the spare parts supply chain", Computers in Industry, Vol. 65 No. 1, pp. 50-63.

Khajavi, S.H., Partanen, J., Holmström, J. and Tuomi, J. (2015), "Risk reduction in new product launch: a hybrid approach combining direct digital and tool-based manufacturing", Computers in Industry, Vol. 74, pp. 29-42.

Kietzmann, J., Pitt, L. and Berthon, P. (2015), "Disruptions, decisions, and destinations: Enter the age of 3-D printing and additive manufacturing", Business Horizons, Vol. 58 No. 2, pp. 209-215.

Kilpi, J., Töyli, J. and Vepsäläinen, A. (2009), "Cooperative strategies for the availability service of repairable aircraft components", International Journal of Production Economics, Vol. 117 No. 2, pp. 360-370.

Kohtala, C. (2015), "Addressing sustainability in research on distributed production: an integrated literature review", Journal of Cleaner Production, Vol. 106, pp. 654-668.

Kruth, J.-P., Leu, M.C. and Nakagawa, T. (1998), "Progress in Additive Manufacturing and Rapid Prototyping”, CIRP Annals - Manufacturing Technology, Vol. 47 No. 2, pp. 525540.

Lindemann, C., Jahnke, U., Moi, M. and Koch, R. (2012), “Analyzing product lifecycle costs for a better understanding of cost drivers in additive manufacturing", Solid Freeform Fabrication Proceedings, presented at the 23th Annual International Solid Freeform Fabrication Symposium, University of Texas, Austin, TX, pp. 177-188.

MacCarthy, B. L., Blome, C., Olhager, J., Srai, J. S., \& Zhao, and X. (2016). Supply chain evolution-theory, concepts and science. International Journal of Operations \& Production Management, Vol. 36 No. 12, pp. 1696-1718.

Mellor, S., Hao, L. and Zhang, D. (2014), “Additive manufacturing: A framework for implementation", International Journal of Production Economics, Vol. 149, pp. 194201.

Mehnen, J., Ding, J., Lockett, H. and Kazanas, P. (2014), "Design study for wire and arc additive manufacture", International Journal of Product Development 20, Vol. 19 No. $1-3$, pp. 2-20.

Nyman, H.J. and Sarlin, P. (2014), "From Bits to Atoms: 3D Printing in the Context of Supply Chain Strategies", presented at the 47th Hawaii International Conference on System Sciences, pp. 4190-4199.

Pérès, F. and Noyes, D. (2006), "Envisioning e-logistics developments: Making spare parts in situ and on demand: State of the art and guidelines for future developments", Computers in Industry, Vol. 57 No. 6, pp. 490-503.

Petersen, E., Kidd, R. and Pearce, J. (2017), "Impact of DIY Home Manufacturing with 3D Printing on the Toy and Game Market", Technologies, Vol. 5 No. 3, p. 45. 
Petrick, I.J. and Simpson, T.W. (2013), “3D Printing Disrupts Manufacturing: How Economies of One Create New Rules of Competition”, Research-Technology Management, Vol. 56 No. 6, pp. 12-16.

Petrovic, V., Vicente Haro Gonzalez, J., Jordá Ferrando, O., Delgado Gordillo, J., Ramón Blasco Puchades, J. and Portolés Griñan, L. (2011), "Additive layered manufacturing: sectors of industrial application shown through case studies", International Journal of Production Research, Vol. 49 No. 4, pp. 1061-1079.

Potter, A., Towill, D.R. and Christopher, M. (2015), "Evolution of the migratory supply chain model”, Supply Chain Management: An International Journal, Vol. 20 No. 6, pp. 603612.

Rayna, T. and Striukova, L. (2014), "The impact of 3D printing technologies on business model innovation”, Digital Enterprise Design \& Management, Springer, pp. 119-132.

Rayna, T., Striukova, L. and Darlington, J. (2015), "Co-creation and user innovation: The role of online 3D printing platforms", Journal of Engineering and Technology Management, Vol. 37, pp. 90-102.

Rayna, T. and Striukova, L. (2016), "From rapid prototyping to home fabrication: How 3D printing is changing business model innovation", Technological Forecasting and Social Change, Vol. 102, pp. 214-224.

Rogers H., Baricz N., and Pawar K.S. (2017) 3D Printing Services: A Supply Chain Configurations Framework. In: Campana G., Howlett R., Setchi R., Cimatti B. (eds) Sustainable Design and Manufacturing 2017. Springer, Cham.

Rogers, H., Baricz, N. and Pawar, K.S. (2016), "3D printing services: classification, supply chain implications and research agenda", International Journal of Physical Distribution \& Logistics Management, Vol. 46 No. 10, pp. 886-907.

Sasson, A. and Johnson, J.C. (2016), "The 3D printing order: Variability, supercenters and supply chain reconfigurations", International Journal of Physical Distribution \& Logistics Management, Vol. 46 No. 1, pp. 82-94.

Savastano, M., Amendola, C., D'Ascenzo, F. and Massaroni, E. (2016), "3-D Printing in the Spare Parts Supply Chain: An Explorative Study in the Automotive Industry", Digitally Supported Innovation, Springer, Cham, pp. 153-170.

Song, Y.-A. and Park, S. (2006), "Experimental investigations into rapid prototyping of composites by novel hybrid deposition process", Journal of Materials Processing Technology, Vol. 171 No. 1, pp. 35-40.

Steenhuis, H.-J. and Pretorius, L. (2016), "Consumer additive manufacturing or 3D printing adoption: an exploratory study", Journal of Manufacturing Technology Management, Vol. 27 No. 7, pp. 990-1012.

Sun, J., Zhou, W., Huang, D., Fuh, J.Y.H. and Hong, G.S. (2015), “An Overview of 3D Printing Technologies for Food Fabrication", Food and Bioprocess Technology, Vol. 8 No. 8, pp. 1605-1615.

Wittbrodt, B.T., Glover, A.G., Laureto, J., Anzalone, G.C., Oppliger, D., Irwin, J.L. and Pearce, J.M. (2013), "Life-cycle economic analysis of distributed manufacturing with opensource 3-D printers", Mechatronics, Vol. 23 No. 6, pp. 713-726.

Xiong, X., Zhang, H. and Wang, G. (2009), "Metal direct prototyping by using hybrid plasma deposition and milling”, Journal of Materials Processing Technology, Vol. 209 No. 1, pp. 124-130. 